\title{
Book Review: MARIELla TURRINI - La tartaruga nella cultura dei popoli - Miti, leggende e Folklore
}

\author{
Sebastiano Salvidio ${ }^{1, *}$, Massimo Delfino $^{2,3}$ \\ ${ }^{1}$ Dipartimento di Scienze della Terra, dell'Ambiente e della Vita (DISTAV), Università degli Studi di Genova, I 16132 Genova, Italy \\ 2 Dipartimento di Scienze della Terra, Università di Torino, I 10125 Torino, Italy \\ ${ }^{3}$ Institut Català de Paleontologia Miquel Crusafont, Universitat Autònoma de Barcelona, Cerdanyola del Vallès, Barcelona, Spain \\ *Corresponding author. E-mail: sebastiano.salvidio@unige.it
}

The title of this book, written in Italian, may be translated as: "Turtles in people's Culture - Myths, Legends and Folklore". The author, Mariella Turrini, is an Italian literature teacher loving animals and travels and this book is clearly the outcome of the cross-over of these two beloved passions.

There are nearly no books entirely dedicated to turtles, tortoises and terrapins in culture, art and myth, and therefore this volume seems to fill a real cultural gap. Among the exceptions, worth mentioning is "Tortoise" by Peter Young (2003), an interesting small book with a very different structure and with a much narrower scope. Remarkable, but focused on a single topic, is also the booklet edited by Del Cimmuto (2013) that nicely illustrates a thematic collection of art objects and painting portraying turtles, tortoises and terrapins. Conversely, Mariella Turrini's book is a lengthy, comprehensive work composed by 337 pages of text, 14 pages of notes and 60 illustrations, many of which are original colour artworks and line drawings by the author herself. The long lists of acknowledgments and references testify for a genuine research effort and a solid bibliographic background.

This volume has a well-defined structure. There is a short "Presentation", written by Franco Andreone, herpetologist from the Regional Museum of Natural Sciences of Torino. Then the "Introduction" recalls that it was from the Latin term Testudo that the Italian title word "testuggine" was derived. In the Latin language, testudo was associated not only with the animal, but also to a stringed musical instrument, obtained from its shell (i.e., the Lyra). Moreover, the testudo described a Roman military tight formation, in which rectangular shields were interlocked around and over soldiers underneath, to protect them completely.

After this "Introduction", four short chapters "Symbolism", "Etnomedicine", "Christianity" and "Medieval Age to the Renaissance" are dedicated to the historical use, the popular tales, and the ancient legends associated to turtles, terrapins and tortoises, in the Mediterranean area. It is noteworthy, that in some of these historical societies the turtles, and their symbolic representations, were often associated with a negative belief, in the sense that these animal were often considered belonging to the "Tartarus" the infernal region created by the ancient Greek mythology. However, in more recent cultures these animals assumed a much more positive symbolic meaning and, as stated by Andreone in the "Presentation", are now the only reptiles generally appreciated by humans. Indeed, in many different societies all over the World, these animals are considered harmless, calm, and wise creatures. Moreover, they often became associated with personal longevity, character stability and in general with popular wisdom. Finally, in many societies turtles and tortoises became also the symbolic representation of human fertility.

The book "La tartaruga nella cultura dei popoli", continues with a complete cultural tour around the World representing the core of the volume both in terms of number of pages and amount of information. Indeed, the central and main chapters are dedicated to a well-docu- 
mented and in most cases first-hand description of turtles in art, literature, poetry, myth and cultural traditions of "Europe", "Africa", "Middle East", "Asia", "Oceania", North America", "Central America - Pre-Columbian Societies" and, in the final chapter "Southern America - CircumCaribbean and sub-Andean Societies".

It is clear that this book is the result of many years of passionate work and to the many travels all around the globe, completed by the author Mirella Turrini over the years.

All persons attracted to the many humanistic and cultural aspects related to these strange and very peculiar reptiles could be interested in reading this book, although it is written in Italian and therefore could have a limited distribution. An English translation, maybe omitting or shortening the purely geographical introductory notes to each country in order to avoid a certain dilution of the turtle topics, would be therefore very welcome.

The book "La tartaruga nella cultura dei popoli Miti, leggende e Folklore" is edited and available from Edizioni Belvedere (Latina, Italy) that with this new publication consolidates furthermore its position as a leading publisher of herpetological books.

\section{REFERENCES}

Del Cimmuto, M. (Ed.) (2013): Tartarughe tra arte e scienza: la "Collezione Teresita Olivares Paglione". Quad. Mus. Univ. "G. d'Annunzio" Chieti, 2: 1-111.

Young, P. (2003): Tortoise. Reaktion Books, London. 